\title{
Diet sample collection by esophageal fistula and rumen evacuation techniques
}

\author{
KENNETH C. OLSON
}

\begin{abstract}
Two trials were conducted to compare diet samples collected in the evacuated rumen or through the esophageal fistula. Hypotheses tested were (1) rumen evacuation would not decrease selectivity, (2) being in the rumen during collection would not alter the sample, and (3) both techniques accurately estimated nutritional characteristics of the feed offered. Five steers bifistulated at the esophagus and rumen were used in a grazing and a stall trial. Three collection techniques were used in each trial: rumen collection after evacuation (RC), esophageal collection with the rumen evacuated (ECRE), and esophageal collection with the rumen full (ECRF). Comparison of RC and ECRE assessed the influence of being in the rumen, and ECRE vs ECRF tested selectivity. Hay was sampled before feeding in the stall trial to test hypothesis 3 . All samples were analyzed for organic matter (OM), nitrogen ( $N)$, neutral detergent fiber (NDF), acid detergent fiber (ADF), acid detergent lignin (ADL), hemicellulose, and cellulose. In the grazing trial, collection technique affected only ADL $(P=0.05)$, with ECRE depressed compared to ECRF. Organic matter, N, ADL, and hemicellulose responded $(P<0.05)$ during the stall trial as follows. Salivary ash contamination depressed $\mathrm{OM}(P=0.03)$ in all collected masticate compared to the feed offered. Rumen collection elevated $N(P=0.04)$, but esophageal samples and feed were equal. Hemicellulose was depressed slightly $(P=0.01)$ in all collected masticate. Both techniques elevated ADL $(P=0.001)$, with RC having a greater effect than ECRF. Both collection techniques should provide satisfactory results in grazing trials if precautions are taken. Comparison across techniques appears appropriate if caution is exercised, particularly concerning $\mathbf{N}$ and ADL.
\end{abstract}

Key Words: range nutrition, diet selection, grazing livestock, cattle

Forage selected by grazing animals has been collected for nutri-

\footnotetext{
Author is range scientist, Fort Hays Branch Experiment Station, Kansas State University, Hays 67601 .

Contribution No. 91-269-J from the Kansas Agricultural Experiment Station.

Manuscript accepted 24 March 1990.
}

tional analysis since the development of the esophageal fistula (Torell 1954) and rumen evacuation technique (Lesperance et al. 1960a). The esophageal fistula has been more popular for this purpose (Holechek et al. 1982) because of disadvantages attributed to the rumen evacuation technique. Disadvantages cited include increased time and labor to evacuate and clean the rumen; depressed digestibility if evacuations are repeated thrice or more weekly; unsuitability for cold, open, winter range; adaptability only to large animals; and possible decreased selectivity because of the empty rumen (Van Dyne and Torell 1964, Holechek et al. 1982). Advantages cited for rumen evacuation include ease of fistula maintenance that reduces care requirements, assurance that all ingested forage is collected (Holechek et al. 1982), and possibly more representative sampling by allowing longer collection periods. Because of these advantages, there has been renewed interest in the rumen evacuation technique (Ansotegui et al. 1991, Beverlin et al. 1989). An important unanswered question concerns the possible influence of rumen collection on nutritional components of the masticate, either because of reduced selectivity or alteration of the sample while in the rumen. The hypotheses of this study were that (1) collection in the evacuated rumen would not alter selectivity, (2) being in the rumen would not alter the sample, and (3) both collection techniques provide an accurate estimate of the nutritional value of the forage consumed.

\section{Materials and Methods}

Five 3-year-old Hereford steers (avg. wt. $=675 \mathrm{~kg}$ ) that were bifistulated at the esophagus and rumen were used for both grazing and stall trials. Esophageal fistulae had been established as yearlings, and rumen fistulae were established about 7 weeks before initiation of the study. They were maintained in drylot and fed prairie hay at about $2.4 \%$ of body weight when not in one of the trials. 


\section{Grazing Trial}

The first experiment was conducted on native shortgrass rangeland during a 2-week period from 19-29 September 1989. The site was a 20-ha pasture that had not been grazed during the current year. Principal grass species were western wheatgrass (Agropyron smithii Rydb.), buffalograss (Buchloe dactyloides (Nutt.) Engelm.), and blue grama (Bouteloua gracilis (HBK.) Lag. ex Steud.), with numerous other grass and forb species present in minor amounts. Spring and early summer drought followed by late summer rainfall provided green growth and allowed ample opportunity for diet selectivity to be displayed during the trial. Fistulated steers were placed on the pasture 1 day before sampling began and remained on the pasture during the remainder of the trial.

Three collection procedures were employed: (1) rumen evacuation followed by collection in the rumen (rumen collection: RC), (2) rumen evacuation followed by removal of the esophageal fistula plug and collection in an esophageal collection bag (esophageal collection, rumen evacuated: ECRE), and (3) normal esophageal collection without disturbing the rumen contents (esophageal collection, rumen full: ECRF). The use of these 3 procedures allowed separation of rumen evacuation effects on selectivity (ECRF vs. ECRE) from effects of being in the rumen (ECRE vs. RC). Direct comparison of normal collection procedures (ECRF and RC) would confound these possible effects. Each collection procedure was employed with each steer during each of the 2 weeks of the trial. If a collection was unsuccessful because the steer did not graze or regurgitated rumen contents into an ECRF sample, that collection technique was repeated with that steer later in the week. This provided 2 weekly collections per steer-by-collection technique combination.

Steers were gathered from the pasture at sunrise and prepared for sample collections to occur during normal early morning grazing activity. Rumens were evacuated as described by Lesperance et al. (1960a), except that the rumen wall was washed with a wet sponge. Esophageal samples were collected in screen-bottomed bags that allowed saliva drainage. Steers were allowed to graze for 30 to $\mathbf{4 5}$ minutes and then returned to the pen. Rumen samples were removed immediately by taking most of the solid material, but not scraping the walls or folds in the bottom of the rumen in case former rumen contents had been inadvertently missed during evacuation. A large amount of liquid was often present in the rumen with the sample; liquid that was removed with the solid material remained in the sample, but excess liquid remaining in the rumen after removal of the solid matter was left in the rumen. Any esophageal samples containing regurgitated rumen contents were discarded. All samples were placed in individual tubs, stirred, subsampled into plastic bags, and placed on ice while original rumen contents were returned to the steers. Samples were frozen $\left(-20^{\circ} \mathrm{C}\right)$ until subsequent processing.

\section{Stall Trial}

The second experiment was conducted in individual stalls to compare masticate from each collection technique to the feed offered. This trial was conducted from 31 October through 3 November 1989. Prairie hay in small bales was used as the feed. Samples were collected at 0800 each day. Each morning, 1 bale was randomly selected for that day's collections and core sampled before feeding. This provided 1 hay sample for each day. These samples were stored at room temperature until subsequent processing. Collection procedures were identical to those used in the grazing trial, except ECRE was not evaluated because selectivity was not tested in this trial. Rumen collection and ECRF were performed on each steer in a 2-day period, then the sequence was repeated on the following 2 days to yield 2 collection periods. Following rumen evacuation or attachment of an esophageal collection bag, a small portion (about $3 \mathrm{~kg}$ ) of the core-sampled bale was fed individually to each steer to ensure that all feed was consumed so selection would not be possible. About an hour was required each day to complete collections. Masticate was subsampled and immediately frozen $\left(-20^{\circ} \mathrm{C}\right)$ until subsequent processing. Following return of rumen contents to evacuated steers, additional prairie hay was fed at $1.5 \%$ of body weight. This feed intake was less than that between trials, but was used to provide nominal nutrition while in the stalls, but insure that hunger was not satiated to improve collections.

\section{Laboratory Analysis}

All masticate samples were freeze-dried. Masticate and hay samples were ground in a cyclone mill to pass a $1-\mathrm{mm}$ screen. All samples were analyzed for dry matter, organic matter (OM), and Kjeldahl nitrogen (N) by AOAC (1984) methods. Neutral detergent fiber (NDF), acid detergent fiber (ADF), and acid detergent lignin (ADL) were determined by procedures of Goering and Van Soest (1970), except sodium sulfite and decahydronapthalene were eliminated from the NDF and ADF extractions, and asbestos was eliminated from the ADL extraction. Hemicellulose was calculated as the difference between NDF and ADF, and cellulose was calculated as the percentage weight loss during incubation in $72 \%$ $\mathrm{H}_{2} \mathrm{SO}_{4}$.

\section{Statistical Analysis}

Grazing trial data, including percentage OM, N, NDF, ADF, ADL, hemicellulose, and cellulose, were analyzed by split plot analysis of variance in a randomized complete block design using the General Linear Model procedure of SAS (1985). Steers served as blocks, collection technique as the main plot, and weekly sample periods as subplots (repeated measures). Steers could not be used as experimental units for the stall trial data because individual hay samples were not collected for each steer; instead 1 hay sample had been collected for each day of sampling. Therefore, the 2 collection periods were used as blocks in a randomized complete block design with collection technique (including hay) as the main effect. When $F$ tests were significant $(P \leq 0.05)$, single degree of freedom contrasts were used to test hypotheses $(P \leq 0.05)$. In the grazing trial, these contrasts included ECRF vs. ECRE and ECRE vs. RC. In the stall trial, they included all pairwise combinations of hay, ECRF, and RC. Because percentage data forms a binomial rather than normal distribution, with deviation from normality greater when percentages are outside of the range of 30 to $70 \%$ (Zar 1984), the data were also aresin transformed and analyzed by the same models. However, results of analysis of variance were the same, so orginal percentage data are reported for ease of interpretation.

\section{Results}

\section{Grazing Trial}

The collection technique by sample period interaction was not significant for any dependent variable $(P>0.05)$, and sample period means differed for only 1 variable, $\mathrm{N}(P<0.01)$. Mean $\mathrm{N}$ content of all diets was $1.7 \%$ in week 1 vs. $1.4 \%$ in week 2 . This change was not surprising because forage plants were senescing during this part of the growing season. Dietary nutritional constituents were the same among all collections techniques except ADL content (Table 1), which was lower for ECRE than ECRF, but equal between ECRE and RC.

\section{Stall Trial}

Several nutritional constituents were altered by or among collection techniques (Table 2). Organic matter content was depressed equally by both collection techniques compared to the feed offered. Nitrogen was similar between feed and ECRF, but was increased in RC samples. Neutral detergent fiber, ADF, and cellulose content were not affected by collection techniques. Hemicellulose content 
Table 1. Nutritional composition of masticate collected by 3 techniques from steers grazing native shortgrass range.

\begin{tabular}{|c|c|c|c|c|c|}
\hline \multirow[b]{2}{*}{ Nutritional component } & \multicolumn{3}{|c|}{ Collection technique } & \multirow[b]{2}{*}{$\mathrm{SE}^{4}$} & \multirow[b]{2}{*}{$\mathbf{P}^{5}$} \\
\hline & ECRF 1 & ECRE $^{2}$ & $\mathbf{R C}^{3}$ & & \\
\hline Organic matter & $\begin{array}{l}-. \% \\
85.3\end{array}$ & $\begin{array}{l}\text { f dry ma } \\
86.9\end{array}$ & 83.5 & 1.74 & 0.43 \\
\hline $\begin{array}{l}\text { Nitrogen } \\
\text { Neutral detergent fiber } \\
\text { Acid detergent fiber } \\
\text { Acid detergent lignin } \\
\text { Hemicellulose } \\
\text { Cellulose }\end{array}$ & $\begin{array}{c}-\% \text { of } \\
1.6 \\
67.1 \\
34.9 \\
6.6^{\mathrm{a}} \\
32.2 \\
25.7\end{array}$ & $\begin{array}{c}\text { organic } \\
1.4 \\
70.1 \\
36.8 \\
5.5^{b} \\
33.3 \\
28.9\end{array}$ & $\begin{array}{r}\text { atter- - } \\
1.7 \\
68.9 \\
36.5 \\
5.6 \\
32.3 \\
26.9\end{array}$ & $\begin{array}{l}0.10 \\
1.41 \\
0.83 \\
0.26 \\
1.07 \\
1.19\end{array}$ & $\begin{array}{l}0.22 \\
0.36 \\
0.27 \\
0.05 \\
0.72 \\
0.22\end{array}$ \\
\hline
\end{tabular}

1ECRF = esophageal collection, rumen full.

2ECRE = esophageal collection, rumen evacuated

${ }^{3} \mathrm{RC}=$ rumen collection

$4 \mathrm{SE}=$ standard error $(n=5)$.

sProbability of hypothesis that collection technique means are equal.

a,b ECRF and ECRE differed $(P<0.05)$

Table 2. Nutritional composition of feed and masticate collected by 2 techniques from steers fed in individual stalls.

\begin{tabular}{|c|c|c|c|c|c|}
\hline \multirow[b]{2}{*}{ Nutritional component } & \multicolumn{3}{|c|}{ Collection technique } & \multirow[b]{2}{*}{$\mathrm{SE}^{3}$} & \multirow[b]{2}{*}{$\mathbf{P}^{4}$} \\
\hline & hay & ECRF $^{1}$ & $\mathbf{R C}^{2}$ & & \\
\hline \multirow{3}{*}{ Organic matter } & \multicolumn{3}{|c|}{$\ldots$. \% of dry matter $\ldots$} & & \\
\hline & $92.7^{a}$ & $91.3^{\mathrm{b}}$ & $90.6^{b}$ & 0.28 & 0.03 \\
\hline & \multicolumn{3}{|c|}{$-\%$ of organic matter - - } & & \\
\hline Nitrogen & $0.9^{\mathrm{a}}$ & $1.0^{\mathrm{a}}$ & $1.2^{\mathrm{b}}$ & 0.04 & 0.04 \\
\hline Neutral detergent fiber & 75.8 & 75.3 & 76.3 & 0.33 & 0.13 \\
\hline Acid detergent fiber & 39.7 & 40.6 & 41.3 & 0.24 & 0.06 \\
\hline Acid detergent lignin & $4.7^{\mathrm{2}}$ & $5.6^{\mathrm{b}}$ & $6.5^{c}$ & 0.06 & 0.001 \\
\hline Hemicellulose & $36.1^{2}$ & $34.7^{\mathrm{b}}$ & $35.0^{\mathrm{b}}$ & 0.19 & 0.01 \\
\hline Cellulose & 34.1 & 34.3 & 34.2 & 0.29 & 0.95 \\
\hline
\end{tabular}

IECRF = esophageal collection, rumen full.

${ }^{2} \mathrm{RC}=$ rumen collection.

${ }^{3} \mathrm{SE}=$ standard error $(n=5)$.

4Probability of hypothesis that collection technique means are equal.

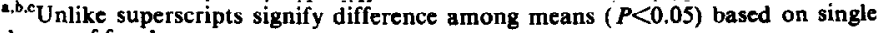
degree of freedom contrasts.

was depressed equally by both collection techniques compared to feed offered. Acid detergent lignin was increased in all masticate compared to feed offered and was greater in RC than ECRF.

\section{Discussion}

The lack of difference among collection techniques for most nutritional variables during the grazing trial (Table 1) indicated that the rumen evacuation technique did not affect selectivity or alter the sample while in the rumen. The one constituent that did differ among techniques, ADL, indicated a change in selectivity. However, the response was not as expected. One would expect that reduced selectivity because of evacuation of the rumen would lead to increased levels of cell wall constituents including lignin, not decreased amounts, as indicated in this trial. Lesperance et al. (1960b) reported similar results for N comparing ECRF to RC. They found crude fiber was the same in 3 trials, but was greater in RC compared to ECRF in a fourth trial, as compared to no changes in NDF or ADF and a decrease in ADL in the present study.

Four of the 7 nutritional variables were affected by collection technique during the stall trial (Table 2). The increased statistical precision during the stall trial resulted from reduced variability because the opportunity to select a diet was eliminated and a very uniform quality hay was used (coefficients of variation for nutri- tional constituents among the 4 hay samples ranged from 0.1 to $3.6 \%)$.

Decreased organic matter content of masticate samples (Table 2) as a result of salivary mineral contamination has been well documented with both esophageal (Lesperance et al. 1960a, Hoehne et al. 1967, Scales et al 1974) and rumen collections (Lesperance et al. 1960a, Bohman and Lesperance 1967). Reporting nutritional data from masticate on an OM basis (Wallace et al. 1972) overcomes this problem.

Lesperance et al. (1960a) found that $\mathrm{N}$ content was equal between esophageal and rumen samples. Comparisons between feed offered and esophageal or rumen collections have yielded mixed results. Bath et al. (1956) reported increased N; Lesperance et al. (1960a) and Kiesling et al. (1969) reported no change; and Hoehne et al. (1967) reported decreased $N$ in esophageal collections compared to the forage offered. Marshall et al. (1967) and Scales et al. (1974) reported variable results. Lesperance et al. (1960a) and Galt and Theurer (1976) found no effect, whereas Bohman and Lesperance (1967) found increased $N$ in rumen samples compared to forage offered. Barth and Kazzal (1971) felt that leaching of $\mathbf{N}$ from samples through screen-bottom bags probably equalled salivary $\mathbf{N}$ contamination, thus explaining equal results, with elevated $\mathbf{N}$ expected from solid-bottom esophageal bags. Rumen collections might be expected to be similar to solid-bottom bags. This could explain our results. However, comparison of bag type with $\mathrm{N}$ response among the above citations does not support this theory. Scales et al. (1974) postulated that this saliva/ leaching balance could be complicated by low $\mathrm{N}$ feeds, wherein salivary contamination exceeded loss by leaching, yielding elevated masticate N. Again, considering this along with bag type, the above citations are not supportive. Marshall et al. (1967) suggested that salivary $\mathbf{N}$ contamination is a function of $\mathbf{N}$ concentration of the forage evaluated vs. $\mathbf{N}$ concentration of the basal ration (through its influence on blood urea and salivary $\mathbf{N}$ ). If $\mathbf{N}$ concentration of the test feed is much less than that of the basal ration, salivary contamination will influence the $\mathrm{N}$ concentration of the masticate more than equal $\mathbf{N}$ or elevated $\mathbf{N}$ in the test feed. In the stall trial, the basal diet fed before and during the trial was the same forage as that evaluated. Dry, fibrous feeds (usually those low in N) stimulate salivary production, exacerbating $\mathbf{N}$ contamination of low $\mathbf{N}$ forages (Marshall et al. 1967). This situation was possible with the low $\mathrm{N}$ and dryness of the hay offered in the stall trial, but was not evident in the grazing trial because of the higher overall $\mathrm{N}$ content and relative lushness of the diet. However, the effect in the stall trial would be expected to be equal across collection techniques. Additional $\mathbf{N}$ contamination above that possible from salivary $\mathbf{N}$ appears to be affecting RC, such as direct infusion of urea from blood to the rumen (Wallace et al. 1972). Blood urea diffuses rapidly into the rumen as ammonia, with rate of diffusion directly related to the gradient (Church 1976). Thus, low N diets contribute to this process (ibid). Presumably, evacuating the rumen would maximize this gradient. Calculations indicated that 5-10 times as much ammonia entered the rumen by diffusion as from saliva (Church 1976). Galt and Theurer (1976), using animals on a low N forage, discovered that the $\mathrm{N}$ concentration in fluid found in the rumen after a collection was 4 to 12 times greater than that in saliva. They did not attribute this increase to leached $\mathrm{N}$ from the sample, because they had found masticate $\mathrm{N}$ and feed $\mathrm{N}$ to be equal in a separate trial. Although this finding indirectly supports the contention that $\mathbf{N}$ is entering the rumen through the wall, it disagrees with the finding that this causes increased $\mathbf{N}$ in the masticate. While it appears increased $\mathrm{N}$ in RC samples may not be universal, precautions should be taken to minimize the effect. Lesperance et al. (1974) suggested that fistulated animals should be maintained on basal rations similar to the diet collected. This 
appears to be particularly true with low $\mathrm{N}$ forages wherein salivary and/or ruminal $\mathbf{N}$ have greater opportunity to elicit a bias. Additionally, length of rumen collection periods should be shortened to limit the opportunity for $\mathbf{N}$ influx to contaminate the sample.

Most of the fiber fractions exhibited little response to collection techniques (Table 2). Collection technique means for NDF, ADF, and cellulose were all similar and equal to the hay offered. However, hemicellulose was depressed with both collection techniques compared to the hay offered. Overall, differences in hemicellulose do not appear to be biologically significant, partly because the relative differences among values were small, but more importantly because the 2 variables from which hemicellulose is calculated, NDF and ADF, were not affected. Little (1972) reported a similar response for NDF. Lascano et al. (1970) agreed that ADF did not increase in esophageal collections, but most researchers found that it increased in both esophageal (Hoehne et al. 1967, Barth et al. 1970, Barth and Kazzal 1971) and ruminal (Lascano et al. 1970) collections. Scales et al. (1974) found that ADF response depended on forage type, with no increase using grass, but an increase using a legume. If one assumes that crude fiber response would be indicative of ADF response, Lesperance et al. (1960a) and Marshall et al. (1967) found that crude fiber content of ruminal and esophageal masticate increased, whereas Kiesling et al. (1969) reported mixed results similar to Scales et al. (1974). Only Bath et al. (1956) reported that crude fiber content of masticate equalled the feed offered. All of these analyses were performed on air- or oven-dried samples, except for a few cases (Lascano et al. 1970, Scales et al. 1974) wherein drying technique was another variable of interest. In these cases, drying technique did not influence results. However, others have indicated that drying technique influences results of fiber analyses (Bohman and Lesperance 1967, Burritt et al. 1988), with freeze-drying being the only method that never artificially elevated fiber fractions in masticate samples because of formation of artifact lignin during the drying process. Thus, many of these studies using air- and oven-drying reported elevated fiber fractions, but freeze-drying prevented it in the current study in fractions except ADL.

Acid detergent lignin was the only fiber fraction that displayed a significant and important response to collection techniques (Table 2). Both collection techniques elevated ADL compared to hay offered, and RC elevated it above ECRF. Apparently, increasing levels of contact with the animal additively increased the ADL content of the sample. This response among collection techniques is opposite of that observed in the grazing trial, but is as expected. Barth et al. (1970) and Barth and Kazzal (1971) also found ADL to be elevated in esophageal masticate, but Bath et al. (1956) and Hoehne et al. (1967) found similar ADL in esophageal masticate and feed. Hoehne et al. (1967) also found that soluble carbohydrates were decreased in the esophageal masticate and attributed this to leaching with saliva through screen-bottom bags. They did not attribute this decrease to artifact lignin formation because of inconsistent increases in ADF and no increases in ADL. Barth et al. (1970) attributed increased ADF and ADL in esophageal masticate to both leaching of soluble carbohydrates and formation of artifact lignin. Lascano et al. (1970) found that esophageal masticate was similar to the feed offered, but ADL was elevated in ruminal masticate. They immediately froze esophageal masticate, but left ruminal masticate in the rumen for $45 \mathrm{~min}$., possibly allowing non-enzymatic browning to form more artifact lignin in the ruminal masticate than the esophageal masticate. In the current study, all sample collections periods were of equal length, and all masticate was immediately frozen. However, Scales et al. (1974) and Acosta and Kothmann (1978) compared immediate freezing with delays of 1 and 4 hours, respectively, and reported no effect on fiber constituents of esophageal masticate. Lascano et al. (1970) also collected esophageal masticate by reaching into the rumen and catching masticate as it came through the esophageal cardia. This probably reduced the leaching loss of soluble carbohydrates that occurred from using screen-bottom bags in the current study. This would explain the discrepancies between studies in comparisons of esophageal masticate to feed offered. As with N, RC appears to have an influence on ADL beyond that attributable to salivary effects. Lascano et al. (1970) attributed it to leaching and absorption in the rumen, as well as formation of artifact lignin. Artifact lignin formation was evident because acid-detergent-insoluble nitrogen (ADIN) was elevated in RC regardless of drying technique, but was not elevated in esophageal samples. This occurred despite freeze-drying of all masticate samples. Disappearance of soluble carbohydrates from masticated forage in the rumen probably does increase their loss over that of leaching only from esophageal collections. Lesperance et al. (1974) also concluded that disappearance occurred because total carbohydrates in RC were slightly reduced compared to the same feed soaked in artificial saliva. However, they also concluded that artifact lignin formation probably played a greater role in alteration of $\mathrm{RC}$. Previous citations concerning delayed freezing lead to the opposite conclusion: that disappearance may play a greater role than artifact lignin formation. As with $\mathbf{N}$ contamination, these effects do not appear to be universal in all situations, but precautions should be taken in all cases to prevent them, such as limited length of collection periods to minimize the opportunity for disappearance and non-enzymatic browning to occur.

\section{Conclusions and Implications}

Based on the grazing trial, only one variable, $A D L$, indicated a possible effect of rumen evacuation on selectivity. However, the reduction in ADL was the opposite of that necessary to support the hypothesis that rumen evacuation would reduce selectivity. There were no changes in nutritional composition of the masticate to indicate that being in the rumen affected the samples.

Reduced variability because of blocked selectivity and uniform hay use during the stall trial increased the number of nutritional characteristics displaying significant responses to collection techniques. Although this level of precision may not be typical of grazing trials in which these techniques are used, the results are still enlightening concerning potential sources of error. The largest and most biologically significant effects were increased $\mathbf{N}$ content of RC and increased ADL content of both ECRF and RC. These changes indicate that being in the evacuated rumen may alter the sample. Nitrogen elevation probably resulted from ammonia $\mathbf{N}$ influx from the blood. Increased ADL in ECRF probably resulted indirectly from leaching of soluble fractions through the screenbottom bags. Increased ADL in RC above that in ECRF was probably a reflection of soluble carbohydrate loss through disappearance while the sample was in the rumen, as well as some formation of artifact lignin before removal from the rumen and freezing. These changes in RC may possibly be minimized by using relatively short collection periods (30-45 $\mathrm{min}$ ) to reduce the opportunity for the changes to occur. Unfortunately, this negates the proposed advantage of $\mathrm{RC}$ that collection periods can be longer to allow a more representative sample of the diet to be collected.

Either technique should provide useful and valid results in grazing trials, as long as precautions stated above are followed. Comparison of data across techniques appears appropriate, but caution should be exercised, particularly concerning $N$ and ADL. A researcher's choice of technique should be based on the situation for which the fistulated livestock are needed, labor resources in relation to collection and animal care requirements, and location and ease of handling fistulated livestock for necessary fistula care. Finally, a bonus of rumen fistulae to be considered is the versatility 
to collect other data, including ruminal fermentation characteristics and kinetics.

\section{Literature Cited}

Acosta, R.A., and M.M. Kothmann. 1978. Chemical composition of esophageal-fistula forage samples as influenced by drying method and salivary leaching. J. Anim. Sci. 47:691-698.

Ansotegui, R.P., K.M. Havstad, J.D. Wallace, and D.M. Hallford. 1991. Effects of milk intake on forage intake and performance of suckling range calves. J. Anim. Sci. 69:899-904.

AOAC. 1984. Official methods of analysis (14th Ed.). Association of Offic. Analyt. Chem. Washington, D.C.

Barth, K.M., J.E. Chandler, M.E. Fryer, and H.C. Wang. 1970. Effects of saliva and drying temperature on composition and digestibility of forage samples collected through esophageal fistulas. J. Anim. Sci. 31:794-798,

Barth, K.M., and N.T. Kazzal. 1971. Separation of true selective grazing by cattle from effects of the esophageal fistula. J. Anim. Sci. 33:1124-1128.

Bath, D.L., W.C. Weir, and D.T. Torell. 1956. The use of the esophageal fistula for the determination of consumption and digestibility of pasture forage by sheep. J. Anim. Sci. 15:1166-1171.

Beverlin, S.K., K.M. Havstad, E.L. Ayers, and M.K. Peterson. 1989. Forage intake responses to winter cold exposure of free-ranging beef cows. Appl. Anim. Behav. Sci. 23:75-85.

Bohman, V.R., and A.L. Lesperance. 1967. Methodology research for range forage evaluation. J. Anim. Sci. 26:820-826.

Burritt, E.A., J.A. Prister, and J.C. Malechek. 1988. Effect of drying method on the nutritive composition of esophageal fistula forage samples: influence of maturity. J. Range Manage. 41:346-349.

Church, D.C. 1976. Digestive physiology and nutrition of ruminants. Vol. 1. Digestive physiology (2nd Ed.). Oxford Press, Portland, Ore.

Galt, H.D., and B. Theurer. 1976. Salivary nitrogen contamination in rumen fistula forage samples. J. Anim. Sci. 42:1272-1279.

Goering, H.K., and P.J. Van Soest. 1970. Forage fiber analyses. USDAARS Agr. Handbk. 379.

Hoehne, O.E., D.C. Clanton, and C.L. Streeter. 1967. Chemical changes in esophageal fistula samples caused by salivary contamination and sample preparation. J. Anim. Sci. 26:628-631.
Holechek, J.L., M. Vavra, and R.D. Pieper. 1982. Methods for determining the nutritive quality of range ruminant diets: A review. J. Anim. Sci. 54:363-376.

Kiesling, H.E., A.B. Nelson, and C.H. Herbel. 1969. Chemical composition of tobosa grass collected by hand-plucking and esophageal-fistulated steers. J. Range Manage. 22:155-159.

Lascano, C.E., B. Theurer, H.A. Pearson, and W.H. Hale. 1970. Factors influencing fiber and lignin content of rumen fistula forage. Proc. West. Sec. Amer. Soc. Anim. Sci. 21:87-92.

Lesperance, A.L., V.R. Bohman, and D.W. Marble. 1960a. Development of techniques for evaluating grazed forage. J. Dairy Sci. 43:682-689.

Lesperance, A.L., D.C. Clanton, A.B. Nelson, and C.B. Theurer. 1974. Factors affecting the apparent chemical composition of fistula samples. Nevada Agr. Exp. Sta. Bull. T-18.

Lesperance, A.L., E.H. Jensen, V.R. Bohman, and R.A. Madsen. 1960 b. Measuring selective grazing with fistulated steers. J. Dairy Sci. 43:1615-1622.

Little, D.A. 1972. Studies on cattle with oesophageal fistulae. The relation of the chemical composition of feed to that of the extruded bolus. Australian J. Exp. Agr. and Anim. Husb. 12:126-130.

Marshall, B., D.T. Torell, and R.M. Bredon. 1967. Comparison of tropical forages of known composition with samples of these forages collected by esophageal fistulated animals. J. Range Manage. 20:310-313.

SAS. 1985. SAS /STAT user's guide for personal computers, Version 6 Ed., SAS Institute, Inc., Cary, N.C.

Scales, G.H., C.L. Streeter, A.H. Denham, and G.M. Ward. 1974. Effect of mastication, salivary contamination and leaching on the chemical composition of forage samples collected via esophageal fistulae. J. Anim. Sci. 38:1278-1283.

Torell, D.T. 1954. An esophageal fistula for animal nutrition studies. J. Anim. Sci. 13:878-884.

Van Dyne, G.M., and D.T. Torell. 1964. Development and use of the esophageal fistula: a review. J. Range Manage. 17:7-19.

Wallace, J.D., D.N. Hyder, and G.M. Van Dyne. 1972. Salivary contamination of forage selected by esophageal fistulated steers grazing sandhill grassland. J. Range Manage. 25:184-187.

Zar, J.H. 1984. Biostatistical analysis. Prentice-Hall, Englewood Cliffs, N.J. 